\title{
SISTEM INFORMASI PENGOLAHAN DATA PENDUDUK DAN SURAT KEPENDUDUKAN PADA DESA PASAREAN
}

\author{
Angga Landesta ${ }^{1}$, Intan Mutia ${ }^{2}$, Muhammad Nur El Farabi ${ }^{3}$ \\ ${ }^{1,2,3}$ Universitas Indraprasta PGRI \\ Jl. Raya Tengah No. 80, Kel. Gedong, Kec. Pasar Rebo, Jakarta Timur 13760, Jakarta \\ 1anggalandesta@gmail.com, ${ }^{2}$ as.syifaraa@gmail.com, ${ }^{3}$ mnurelfarabi@gmail.com
}

\begin{abstract}
ABSTRAK
Desa Pasarean yang terletak di Kecamatan Pamijahan - Kabupaten Bogor ini masih mengimplementasikan metode lama yaitu dengan menggunakan cara manual pada proses pelayanan surat kependudukannya. Tujuan penelitian ini adalah untuk merancang sebuah aplikasi pengolahan data penduduk serta surat kependudukan yang lebih simple agar dapat membantu pelayanan di kantor desa sehingga mengoptimalkan kinerja untuk pelayanan masyarakat tanpa harus melalui birokrasi yang sangat panjang dan menyita waktu masyarakat yang ingin mendapatkan pelayanan kependudukan. Metode yang dipakai ialah dengan metode Research and Development (R\&D) dimana metode ini biasanya dipakai untuk menciptakan sebuah produk serta membuktikan efesiensi dari produk tersebut. Dalam pelaksanaan R\&D ini memakai pendekatan deskriptif untuk untuk mengumpulkan informasi data yang akurat dan untuk metode pengujian menggunakan cara BlackBox Testing untuk memastikan hasilnya apakah sesuai dengan target yang diinginkan serta untuk menguji sistem apakah masih terdapat error atau tidak. Hasil penelitian ini adalah sistem informasi pengolahan data penduduk dan surat kependudukan yang sudah terkomputerisasi yang dapat meningkatkan dan mempermudah kinerja karyawan pada Desa Pasarean.
\end{abstract}

Kata Kunci: pengolahan, data penduduk, surat kependudukan.

\begin{abstract}
Pasarean Village, which is located in Pamijahan District - Bogor Regency, is still implementing the old method, namely by using the manual method in the process of serving the residence certificate. The purpose of this study is to design a simpler application for processing population data and residence certificates in order to assist services at the village office so as to optimize performance for community services without having to go through a very long and time-consuming bureaucracy for people who want to get population services. The method used is the Research and Development $(R \& D)$ method where this method is usually used to create a product and prove the efficiency of the product. In the implementation of this $R \& D$, a descriptive approach is used to collect accurate data information and for the testing method using the BlackBox Testing method to ensure the results are in accordance with the desired target and to test the system whether there are errors or not. The results of this study are a computerized population data processing information system and residence certificate that can improve and facilitate employee performance in Pasarean Village.
\end{abstract}

Key Word: processing, population data, residence certificate.

\section{PENDAHULUAN}

Tugas pokok dan fungsi dari desa ialah menyelenggarakan pelayanan umum kepada masyarakat, permasalahan yang terjadi ialah pelayanan umum masyarakat masih dilakukan secara manual dan harus melalui proses birokrasi yang panjang sehingga tidak efisien. Proses pengelolaan data kependudukan pada desa pasarean masih dilakukan secara manual, sehingga mengakibatkan tidak efisiennya pekerjaan yang dilakukan (Siregar \& Sundari, 2016) Oleh karena itu diperlukannya sistem komputerisasi untuk memudahkan dalam kegiatan input serta pengolahan data penduduk dan surat kependudukan yang dapat diakses dan membantu administrator dalam penyimpanan data masyarakat dan dalam pengisian data pemohon (Mustika et al., 2021) sehinga dapat meminimalisir kesalahan pihak kelurahan dalam pembuatan surat pengantar dan membantu dalam proses pengarsipan dengan (Wati \& Despahari, 2018).

Dalam hal meningkatkan pelayanan yang cepat dan efisien, desa perlu merubah sistem manualnya menjadi sistem yang terkomputerisasi. Hal ini dilakukan untuk meningkatkan pelayanan serta kenyamanan pada masyarakat. 
Berdasarkan permasalahan di atas maka Desa Pasarean membutuhkan suatu sistem informasi yang dapat mendukung pengolahan data penduduk secara cepat, akurat dan tepat serta dapat memberikan kemudahan bagi masyarakat dalam hal pelayanan. Maka dari itu penulis tertarik untuk membuat Sistem Informasi Pengolahan Data Penduduk dan Surat Kependudukan Pada Desa Pasarean yang diharapkan dapat menjadi solusi dari permasalahan yang ada di desa tersebut.

Tujuan dilakukannya penelitian ini adalah membangun suatu rancangan sistem informasi baru dan memberikan solusi untuk masalah yang sering terjadi di Desa Pasarean pada umumnya yaitu pendataan penduduk, keluarga serta pelayanan kependudukan. Untuk menguji serta mengimplementasikan sistem informasi surat kependudukan pada Desa Pasarean. Dan untuk merancang suatu sistem informasi pembuatan laporan data penduduk, data keluarga, serta surat kependudukan di Desa Pasarean.

Perancangan merupakan proses mendefinisikan dikerjakan menggunakan berbagai teknik serta melibatkan deskripsi mengenai arsitektur, detail komponen dan keterbatasan yang akan dialami dalam proses pengerjaannya (Rizky, 2011)

Sistem ialah suatu grup dari subsistem/bagian/komponen baik fisik maupun nonfisik dan berhubungan satu sama lain serta bekerja sama secara harmonis guna mencapai tujuan tertentu (Susanto, 2013) sedangkan untuk komponen sistem informasi terdiri lima sumber daya yang siebut dengan komponen sistem informasi. Kelima sumber daya tersebut yaitu manusia, hardware, software, data, dan jaringan yang masingmasing memiliki peranan yang sangat penting dalam suatu sistem informasi (Sutabri, 2012).

\section{METODE PENELITIAN}

Metode penelitian yang digunakan peneliti dalam melakukan penelitian ini adalah metode Research and Development ( $R \& D)$ merupakan metode penelitian untuk menghasilkan produk tertentu, eserta dapat menguji keefektifan produk tersebut. Produk tersebut tidak selalu berbentuk benda atau perangkat keras (Hardware), misalnya buku, alat tulis, dan alat pembelajaran lainnya.
Selain itu dapat pula dalam bentuk perangkat lunak (Software) (Sugiyono, 2013)

Rancangan kegiatan dimulai dilakukan selama 5 bulan, yakni terhitung pada Maret 2021 sampai dengan Juli 2021 dimulai dengan mengadakan kunjungan langsung ke Desa Pasarean, Bogor yang beralamat di Jl. KH. Abdul Hamid, Pasarean, Kec. Pamijahan, Bogor, Jawa Barat 16810 untuk mencatat halhal penting dan sesuai dengan masalah, lalu melakukan wawancara.

Bahasa pemodelan yang digunakan dalam pembangunan perangkat lunak yaitu menggunakan teknik pemrograman Unified Modeling Language (UML) merupakan bahasa visual untuk menggambarkan, dan membangun serta dokumentasi dari sistem perangkat lunak (Sugiarti, 2013) dan menggunakan database MYSQL untuk menjalankan fungsi pengolahan data (Sibero, 2013), karena database dapat menampung yang besar dan dapat diakses oleh banyak user (Raharjo, 2011) dan aplikasi pengembang yang digunakan adalah XAMPP. XAMPP ialah software open source yang dapat di download secara free dan dapat digunakan di semua sistem operasi seperti windows, linux, solaris, dan mac (Buana, 2014). XАMPP sebuah program web lengkap untuk belajar pemrograman web, khususnya PHP dan MySQL (Nugroho, 2013).

Pengolahan data merupakan rangkaian kegiatan penelitian setelah kegiatan pengumpulan data (Supriyadi, 2014).

NetBeans merupakan aplikasi Integrated Development Environment (IDE) berbasis Java dari Sun Microsystems berjalan diatas swing (Arizona, 2017).

\section{HASIL DAN PEMBAHASAN}

Berdasarkan hasil penelitian masalah sebelumnya, peneliti memberikan analisa permasalahan dari sistem pengelolaan data diantaranya:

1. Proses pendataan penduduk dan keluarga masih dilakukan secara manual sehingga sering terjadi kesalahan-kesalahan penginputan data dan pembuatan laporan masih membutuhkan banyak waktu sehingga tidak efisien.

2. Data yang diolah oleh sistem adalah data keluarga dan data penduduk. 
3. Sistem informasi pengolahan dan penduduk dan surat kependudukan ini akan dirancang dan dibuat dengan bahasa pemrograman Java dan $M y S Q L$ sebagai databasenya.

\section{Dekomposisi Fungsi Sistem yang Diusulkan}

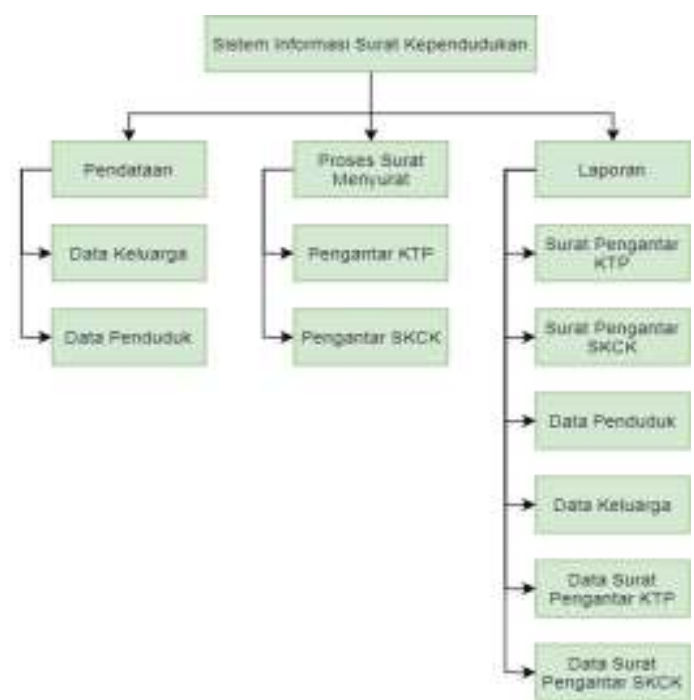

Gambar1. Dekomposisi Fungsi Sistem yang Diusulkan

\section{Unified Modeling Language (UML) Sistem yang Diusulkan}

Use case diagram menggambarkan hubungan antar aktor di dalam sistem informasi surat kependudukan di Desa Pasarean, Bogor

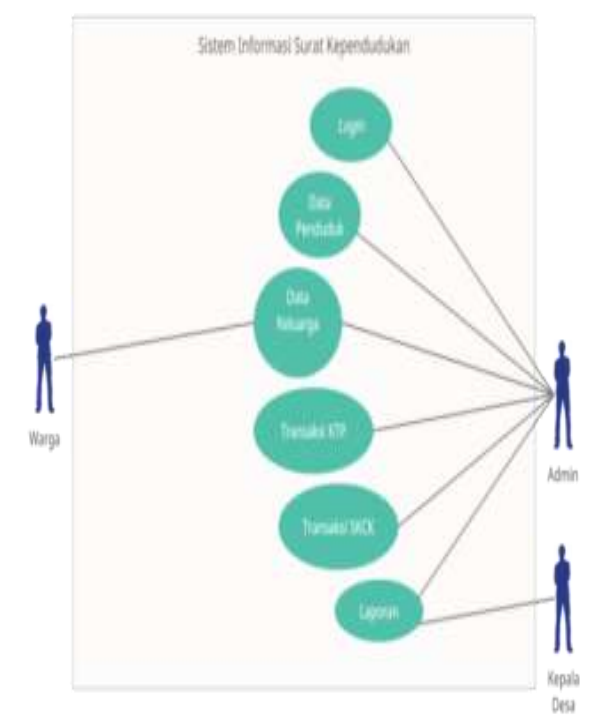

Gambar2. Unified Modeling Language (UML) Sistem yang Diusulkan

\section{Definisi use case Dalam Sistem}

Tabel 1. Use Case Dalam Sistem

\begin{tabular}{|l|l|l|}
\hline No & \multicolumn{1}{|c|}{ Use Case } & \multicolumn{1}{|c|}{ Keterangan } \\
\hline 1 & Login & Akses untuk masuk ke dalam sistem. \\
\hline 2 & Dats Penduduk & $\begin{array}{l}\text { Menambahkan, mengubah, menghapus, dan } \\
\text { mencati data penduduk dalam sistem. }\end{array}$ \\
\hline 3 & Data Keluarga & $\begin{array}{l}\text { Menambahkan, mengubah, menghapus, dan } \\
\text { mencari data keluaga dalam sisten. }\end{array}$ \\
\hline 4 & Transaksi KTP & $\begin{array}{l}\text { Menambahkan, menghapus serta mencetak } \\
\text { surat pengantar KTP. }\end{array}$ \\
\hline 5 & Transaksi SKCK & $\begin{array}{l}\text { Menambahkan, menghapus serta mencetak } \\
\text { surat pengantar SKCK. }\end{array}$ \\
\hline 6 & Laporan & $\begin{array}{l}\text { Melihat data penduduk, data keluxrga dan } \\
\text { surar keluar sers mencetakaya }\end{array}$ \\
\hline
\end{tabular}

Activity Diagram Sistem yang Diusulkan

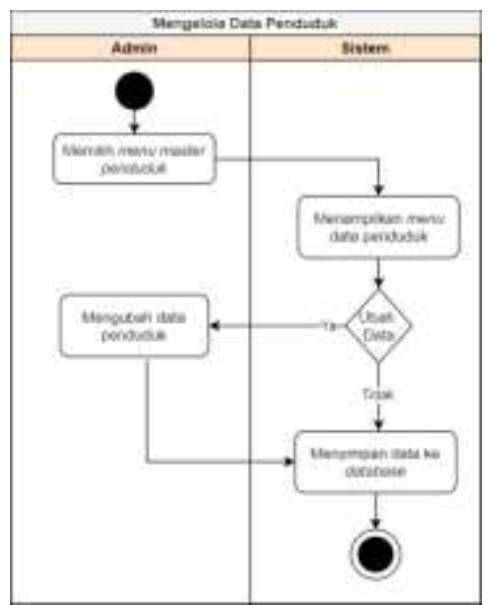

Gambar3. Activity Diagram Sistem yang Diusulkan

Admin masuk ke menu master data penduduk dan kemudian admin dapat menambahkan data penduduk baru, mengubah atau menghapus data penduduk yang telah tersimpan dalam sistem.

\section{Sequence Diagram}

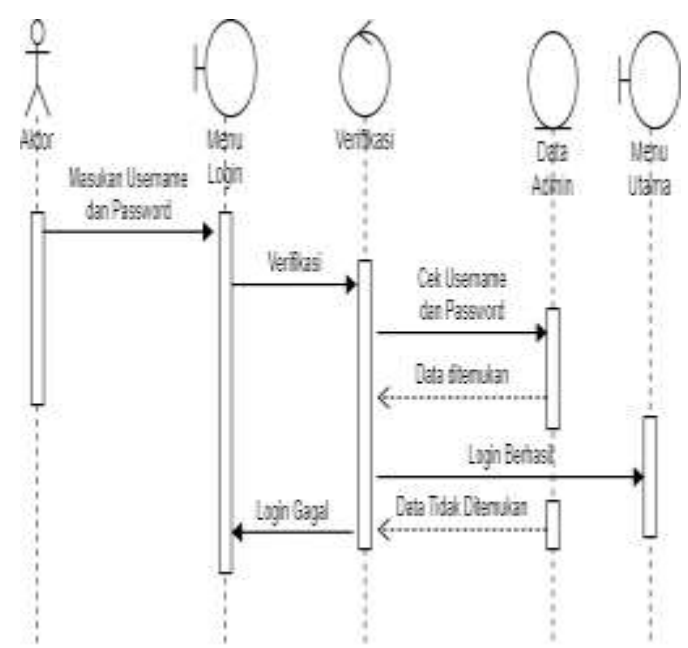

Gambar4. Sequence Diagram

Sequence ini menggambarkan aktor memasuki menu utama sistem dengan 
melakukan login, aktor kemudian memasukan username dan password pada menu login. Setelah itu sistem akan melakukan verifikasi pada database admin. Jika data tidak sesuai maka akan muncul notifikasi 'Login gagal', dan jika data sesuai maka akan muncul notifikasi 'Login berhasil' dan masuk ke menu utama.

\section{Sequence Diagram Mengelola Data Penduduk}

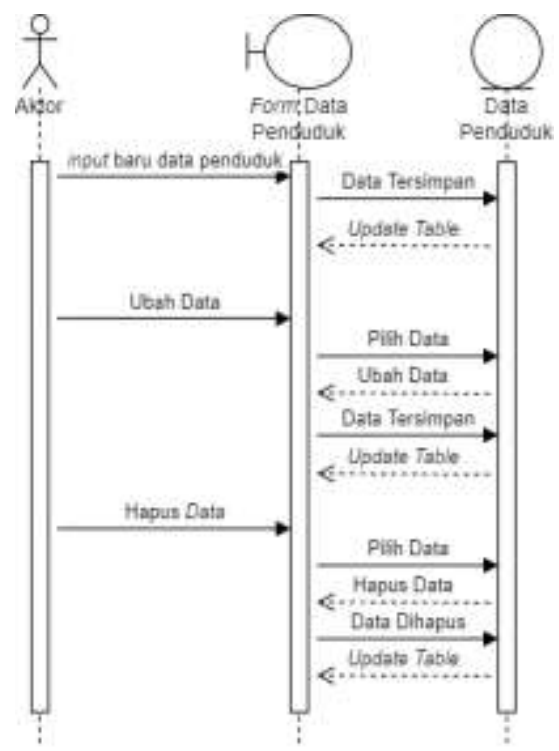

Gambar5. Sequence Diagram Mengelola Data Penduduk

Sequence ini menggambarkan aktor memasuki menu data penduduk kemudian aktor dapat mengisi data penduduk baru, mengubah dan menghapus data penduduk.

\section{Class Diagram yang diusulkan}

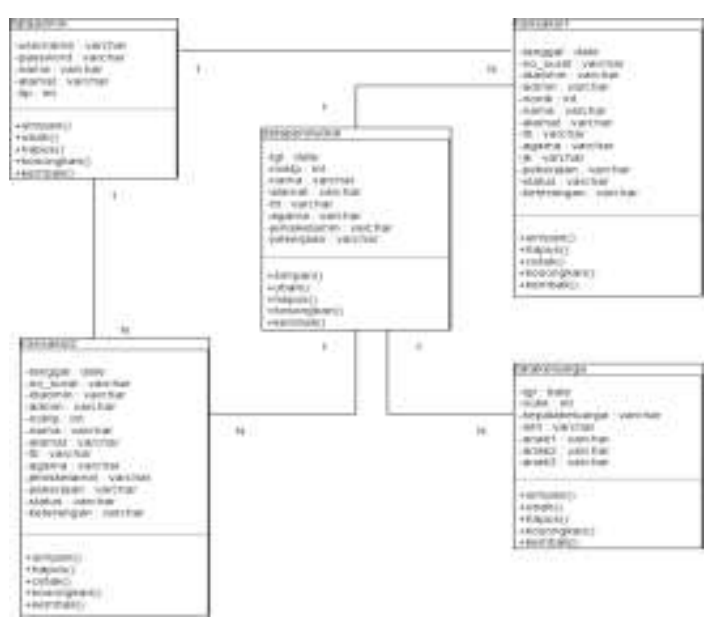

Gambar6. Class Diagram yang diusulkan

\section{Entity Relationship Diagram}

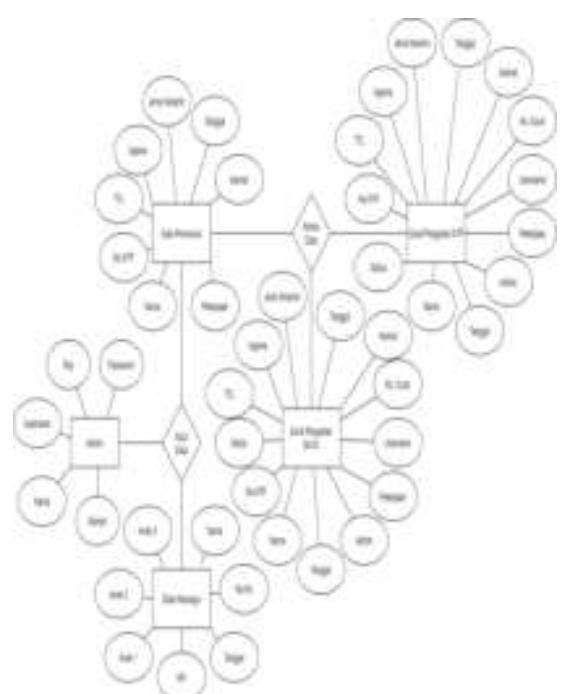

Gambar7. Entity Relationship Diagram

Tampilan Layar (User Interface)

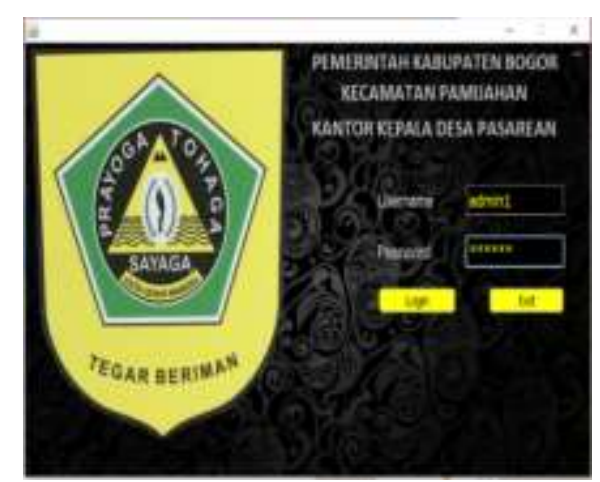

Gambar8. Halaman Login

Tampilan ini terdapat pada awal program. Menu login digunakan sebagai kata kunci sebelum memasuki program utama. Agar tidak sembarang orang dapat mengakses program ini. Sehingga dalam form menu kerahasiaannya tetap terjaga dengan baik.

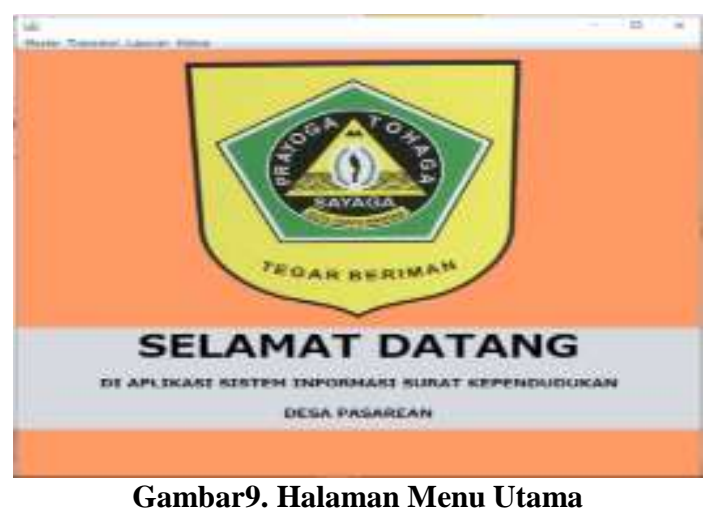

Layar di atas menampilkan tampilan Menu utama pada Sistem Informasi Data Penduduk dan Surat Kependudukan pada Desa Pasarean Bogor. 


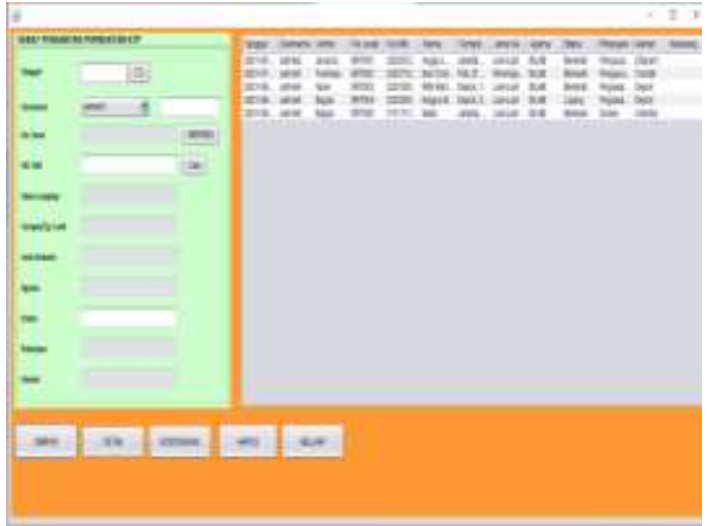

Gambar10. Halaman Form Surat Pengantar Pembuatan KTP

Layar di atas menampilkan tampilan form surat pengantar pembuatan KTP pada layar form tersebut digunakan untuk untuk menginput data Tanggal, Username, No,Surat, NIK, Nama, Tempat Tanggal Lahir, Jenis Kelamin, Agama, Status, Pekerjaan dan Alamat, Keterangan.

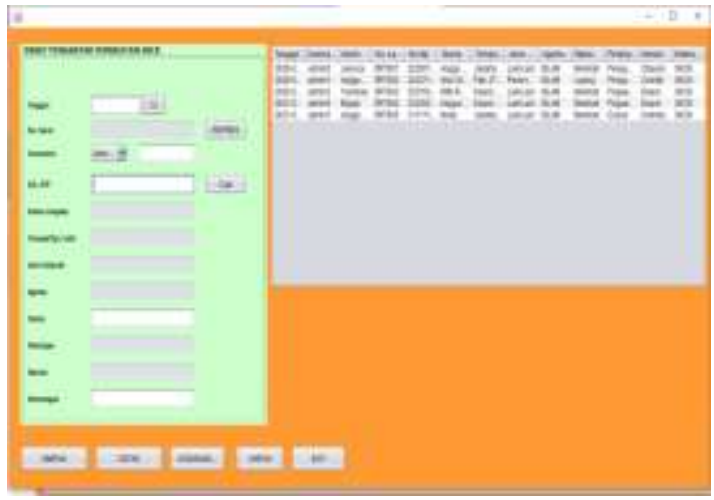

Gambar11. Halaman Form Surat Pengantar Pembuatan SKCK

Layar di atas menampilkan tampilan form surat pengantar pembuatan SKCK pada layar form tersebut digunakan untuk untuk menginput data Tanggal, Username, No,Surat, NIK, Nama, Tempat Tanggal Lahir, Jenis Kelamin, Agama, Status, Pekerjaan dan Alamat, Keterangan.

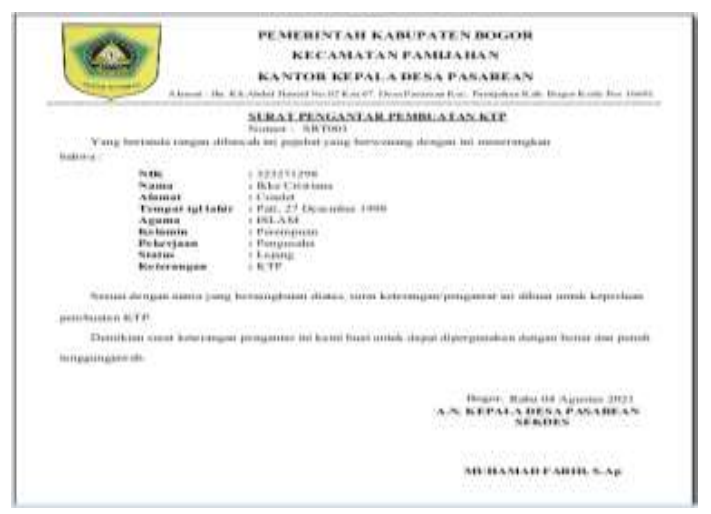

Gambar12. Surat Pengantar KTP
Layar di atas menampilkan tampilan hasil output dari form surat pengantar pembuatan KTP.

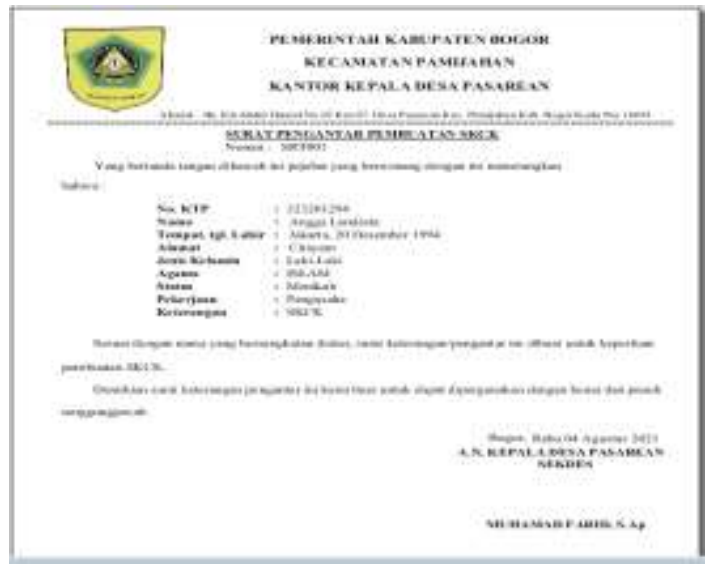

Gambar13. Surat Pengantar SKCK

Layar di atas menampilkan tampilan hasil output dari form surat pengantar pembuatan KTP.

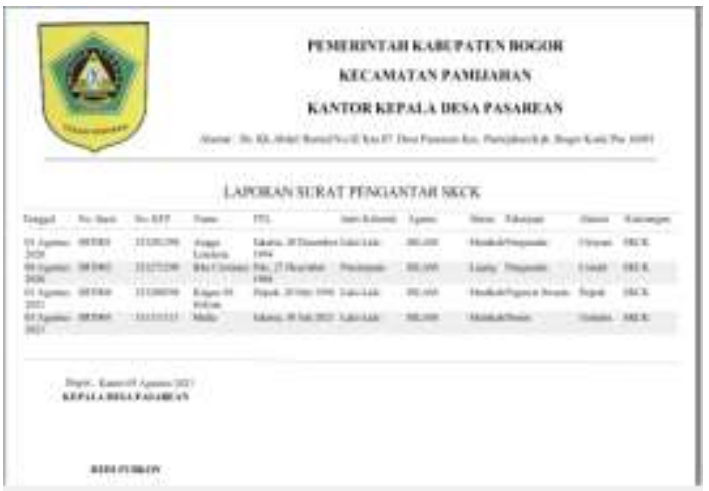

Gambar14. Laporan Data Surat Pengantar SKCK

Layar di atas menampilkan tampilan hasil laporan keseluruhan dari form surat pengantar pembuatan SKCK.

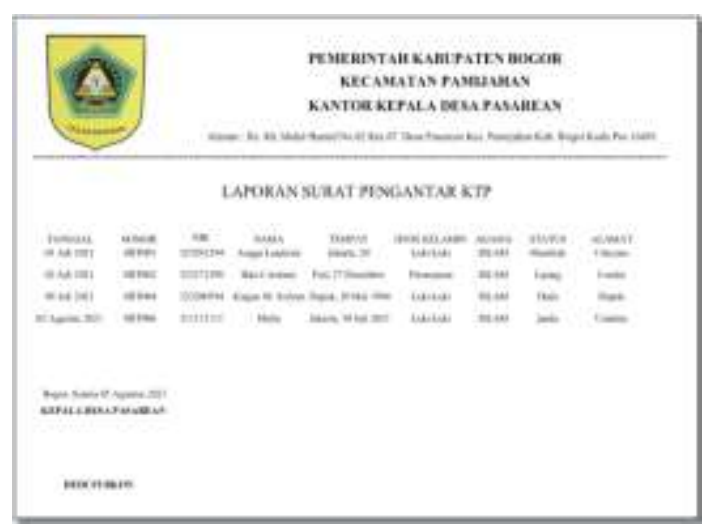

Gambar15. Laporan Surat Pengantar KTP

Layar di atas menampilkan tampilan hasil laporan keseluruhan dari form surat pengantar pembuatan KTP. 
Berdasarkan masalah tersebut maka tahap pengujian dilakukan dengan cara BlackBox Testing. Berikut cara pengujian menjalankan aplikasi dan melihat hasil output-nya apakah telah sesuai dengan hasil yang diharapkan, yaitu :

Tabel2. Pengujian Dengan Metode BlackBox Testing

\begin{tabular}{|c|c|c|c|}
\hline No & Skenario Pengujian & Hasil yang diharapkan & Kesimpulan \\
\hline 1 & $\begin{array}{l}\text { Memasukan usemane } \\
\text { dan passiord yang } \\
\text { belum tersimpan di } \\
\text { database lalu klik } \\
\text { tombol "Login". }\end{array}$ & $\begin{array}{l}\text { Sistem akan menolak dan } \\
\text { menampilkan pesan } \\
\text { "Username atau Password } \\
\text { Salah". }\end{array}$ & Berhasil \\
\hline 2 & $\begin{array}{l}\text { Memasukan username } \\
\text { dan password yang } \\
\text { tersimpan di database } \\
\text { lalu klik "Login". }\end{array}$ & $\begin{array}{l}\text { Sistem akan menampilkan } \\
\text { pesan "Selamat Datang" } \\
\text { dan menuju menu utama. }\end{array}$ & Berhasil \\
\hline 3 & Memilih pilihan menu & & Berhasil \\
\hline 4 & $\begin{array}{l}\text { Pilih form admin, isi } \\
\text { form lalu klik tombol } \\
\text { "simpan" }\end{array}$ & $\begin{array}{l}\text { Data admin alkan } \\
\text { tersimpan di dalam } \\
\text { database dan pada tabel } \\
\text { data admin akan muncul. }\end{array}$ & Berhasil \\
\hline 5 & $\begin{array}{l}\text { Pada halaman admin } \\
\text { pilih data pada tabel } \\
\text { admin kemudian klik } \\
\text { tombol "ubah", lalu } \\
\text { ubah data setelah itu } \\
\text { klik "simpan". }\end{array}$ & $\begin{array}{l}\text { Data yang dipilih dari } \\
\text { tabel admin akan muncul } \\
\text { pada form dan setelah } \\
\text { diubah data tersebut akan } \\
\text { ter-update pada database } \\
\text { dan tabel data admin } \\
\end{array}$ & Berhasil \\
\hline 6 & $\begin{array}{l}\text { Pada halaman admin } \\
\text { pilih data pada tabel } \\
\text { admin kemudian klik } \\
\text { tombol "hapus". }\end{array}$ & $\begin{array}{l}\text { Data akan terhapus dari } \\
\text { database. }\end{array}$ & Berhasil \\
\hline 7 & $\begin{array}{l}\text { Pilih form penduduk, } \\
\text { isi form lalu klik } \\
\text { tombol "simpan" }\end{array}$ & $\begin{array}{l}\text { Data penduduk akan } \\
\text { tersimpan di dalam } \\
\text { database dan pada tabel } \\
\text { data penduduk akan } \\
\text { muncul. }\end{array}$ & Berhasil \\
\hline 8 & $\begin{array}{l}\text { Pada } r \text { halaman } \\
\text { penduduk pilih data } \\
\text { pada tabel penduduk } \\
\text { kemudian klik tombol } \\
\text { "ubah", lalu ubah data } \\
\text { setelah itu klik } \\
\text { "simpan". }\end{array}$ & $\begin{array}{l}\text { Data yang dipilih dari } \\
\text { tabel penduduk akan } \\
\text { muncul pada form dan } \\
\text { setelah diubah data } \\
\text { tersebut akan ter-update } \\
\text { pada database dan tabel } \\
\text { data penduduk }\end{array}$ & Berhasil \\
\hline 9 & $\begin{array}{l}\text { Pada } r \\
\text { penduduk pilih data } \\
\text { pada tabel penduduk } \\
\text { kemudian klik tombol } \\
\text { "hapus". }\end{array}$ & $\begin{array}{l}\text { Data akan terhapus dari } \\
\text { database. }\end{array}$ & Berhasil \\
\hline
\end{tabular}

\section{SIMPULAN DAN SARAN}

Dalam perancangan sistem informasi surat kependudukan pada desa Pasarean, Bogor ini, penulis dapat menarik kesimpulan sebagai berikut: dengan adanya sistem ini diharapkan dapat meningkatkan efisiensi kinerja dalam proses pendataan penduduk, keluarga serta pembuatan surat kependudukan dan laporan pada Desa Pasarean, Bogor. Dengan tersedianya sistem yang sudah terkomputerisasi, diharapkan dapat meningkatkan efektivitas pada pelayanan kependudukan serta pembuatan laporan pada Desa Pasarean, Bogor.

Berdasarkan hasil evaluasi terhadap sistem informasi yang penulis bangun terdapat beberapa saran untuk pengembangan diantaranya adalah pembuatan sistem informasi surat kependudukan ini masih bisa untuk dikembangkan seiring dengan kebutuhan pengguna, terutama dalam hal tampilan sebaiknya dibuat agar lebih menarik. Masih banyak pilihan menu lain yang dapat dikembangkan ke dalam software ini seperti pendataan warga kurang mampu, pengembangan tersebut tentunya dapat meningkatkan mutu kualitas data yang lebih baik serta sesuai dengan permintaan dan kebutuhan dari pemerintah.

\section{DAFTAR PUSTAKA}

Arizona, R. (2017). Peran Team Work Dalam Upaya Meningkatkan Kinerja Karyawan Pada PT. Asuransi Sinarmas Cabang Malang. Jurnal Aplikasi Administrasi, 5260.

Buana. (2014). Aplikasi XAMPP. Andi.

Mustika, W. P., Kumalasari, J. T., Fitriani, Y., \& Abdurohim, A. (2021). Sistem informasi administrasi kependudukan (SIASIK) pada kelurahan berbasis web. Jurnal Sains Komputer Dan Informatika (J-SAKTI), 5(1), 230-240.

https://tunabangsa.ac.id/ejurnal/index.php/js akti

Nugroho, B. (2013). Dasar Pemograman Web $P H P$ - MySQL dengan Dreamweaver. Gava Media.

Raharjo, B. (2011). Belajar Otodidak Membuat Database Menggunakan MySQL. Informatika.

Rizky, S. (2011). Konsep Dasar Rekayasa Perangkat Lunak. PT.Mitra Wacana Media.

Sibero, A. F. . (2013). Web Programming Power Pack. MediaKom.

Siregar, S. R. S., \& Sundari, P. (2016). Rancangan Sistem Informasi Pengelolaan Data Kependudukan Desa (Studi Kasus di Kantor Desa Sangiang Kecamatan Sepatan Timur). Sisfotek Global, 6(1), 76-82.

Sugiarti, Y. (2013). Analisis dan Perancangan UML(Unified Modeling Language) Generated VB. 6. Graha Ilmu.

Sugiyono. (2013). Metodelogi Penelitian Kuantitatif, Kualitatif Dan $R \& D$. Alfabeta.

Supriyadi, E. (2014). SPSS +Amos. In Media.

Susanto, A. (2013). Sistem Informasi Akuntansi. Lingga Jaya.

Sutabri, T. (2012). Analisis Sistem Informasi. Andi.

Wati, M., \& Despahari, E. (2018). Sistem Informasi Pelayanan Administrasi Kependudukan Dan Catatan Sipil Kelurahan Di Kecamatan Marangkayu Kutai Kartanegara. Jurnal Rekayasa Teknologi Informasi (JURTI), 2(1), 47. https://doi.org/10.30872/jurti.v2i1.1379 